\title{
WHAT'S LAW GOT TO DO WITH IT? DIGNITY AND MENSTRUATION
}

\section{ELIZABETH B. COOPER*}

Dignity-dig·ni·ty $\mid \backslash$ 'dig-nə-tē - The "quality or state of being worthy, honored, or
esteemed."

When I think about all that is wrong in the world - the threat to democracy in the United States, ${ }^{2}$ the persistent systemic and individually-inflicted racism, ${ }^{3}$ the devastation wrought by COVID-194-I find myself asking, "Why do I care so much about menstrual laws and policies?" The answer, I have realized, is quite simple: the failure of the

\footnotetext{
${ }^{*}$ Professor, Fordham University School of Law. I am very grateful to Margaret E. Johnson and Marcy L. Karin for inviting me to join their menstrual equity advocacy efforts. I am deeply indebted to Kaitlyn Cunningham and Katherine Mobilia for their extraordinary research, superb ideas, and impressive bluebooking skills.

${ }^{1}$ Dignity, Merriam-Webster Dictionary, https://www.merriam-webster.com/dictionary/dignity [https://perma.cc/D9EN-4QE6].

${ }^{2}$ See Susan D. Hyde \& Elizabeth N. Saunders, Trump Didn't Break Our Democracy. But Did He Fatally Weaken It?, N.Y. TIMES (Dec. 15, 2020), https://www.nytimes.com/2020/12/15/opinion/trump-democracyamerica.html [https://perma.cc/27E7-DWCC] (discussing how President Donald Trump's refusal to accept his 2020 election defeat was a "blatant threat to democracy"); Roger Cohen, A Shattering Blow to America's Troubled Democratic Image, N.Y. TIMES (Jan. 7, 2021), https://www.nytimes.com/2021/01/07/world/europe/macron-merkel-trump-capitol-democracy.html [https://perma.cc/3LJA-5C88] (describing how the Capitol riot on January 6, 2021 threatened American democracy).

${ }^{3}$ See Herstory, BLACK Lives MATTER, https://blacklivesmatter.com/herstory/ [https://perma.cc/3LGP-92RJ] (providing the history of the Black Lives Matter Movement); Nimalan Yoganathan, Black Lives Matter Movement Uses Creative Tactics to Confront Systemic Racism, THe Conversation (July 30, 2020), $\mathrm{https}$ ://theconversation.com/black-lives-matter-movement-uses-creative-tactics-to-confront-systemic-racism143273 [https://perma.cc/3MPJ-T4Y2].

${ }^{4}$ See Coronavirus in the U.S.: Latest Map and Case Count, N.Y. Times (Feb. 28, 2021), https://www.nytimes.com/interactive/2020/us/coronavirus-us-cases.html [https://perma.cc/2PLA-JKET] (showing more than 45 million COVID-19 cases and 736,000 deaths in the U.S. since March 1, 2020); Center for Systems Science and Engineering (CSSE), COVID-19 Dashboard, Johns Hopkins UnIV. \& Med., https://coronavirus.jhu.edu/map.html [https://perma.cc/8ZSU-HMNS] (showing a global map of the COVID19 impact).
} 
government and private institutions to adopt sane, respectful, smart policies concerning menstruation is an affront to dignity.

Myriad policies intruding on a menstruator's right to dignity are described throughout this Symposium and include: failing to include menstrual products in emergencypreparedness or response packages; ${ }^{5}$ not supplying public school students with free access to quality products; ${ }^{6}$ denying free and ready access to such products to people who are incarcerated or detained through our country's immigration policies; ${ }^{7}$ imposing state

\footnotetext{
${ }^{5}$ See Emma Goldberg, Many Lack Access to Pads and Tampons. What Are Lawmakers Doing About It?, N.Y. TiMES (Jan. 13, 2021), https://www.nytimes.com/2021/01/13/us/tampons-pads-period.html [https://perma.cc/M2EP-X4NT] (noting, however, that policies have begun to change for the better). "In March, the Coronavirus Aid, Relief and Economic Security (CARES) Act included provisions allowing menstrual products to be purchased with money from health savings and flexible spending accounts." Id. $C f$. Good Samaritan Menstrual Products Act, H.R. 7054, 116th Cong. (2020) (allowing menstrual products to be donated to and distributed by nonprofit organizations).
}

${ }^{6}$ See Margaret E. Johnson, Emily Gold Waldman \& Bridget J. Crawford, Title IX \& Menstruation, 43 HARV. J. OF L. \& GENDER 225, 225 (2020) (explaining how students attending public schools lack access to menstrual products); Bridget J. Crawford, Margaret E. Johnson, Marcy L. Karin, Laura Strausfeld, \& Emily Gold Waldman, The Ground on Which We All Stand: A Conversation About Menstrual Equity Law and Activism, 26 Mich. J. GENDER \& L. 341, 348, 363, 368 (2019) (describing how schools frequently do not provide access to free menstrual products).

${ }^{7}$ See Crawford et al., supra note 6, at 347 (discussing how incarcerated women in Maryland's jails and prisons did not have adequate access to menstrual products); Chris Bobel \& Breanne Fahs, The Messy Politics of Menstrual Activism, in The Palgrave Handbook of Critical Menstruation Studies 1008 (Chris Bobel, Inga T. Winkler \& Breanne Fahs et al. eds., 2020) [hereinafter PALGRAVE HANDBOOK] ("In prisons and jails, menstrual products are often rationed, restricted, traded, or used by guards in power games. The lack of menstrual supplies among inmates affects not only their hygiene but also their self-esteem."); Alanna Vagianos, Menstruating Migrant Girls 'Visibly' Bleeding Through Pants While Detained, Lawsuit Says, HufFington Post (Aug. 3, 2019, 2:26 PM), https://www.huffpost.com/entry/migrant-girls-borderdetention-menstruating-bleeding-pads_n_5d694102e4b02bc6bb38d026 [https://perma.cc/EBW6-XRGM] (discussing the lack of menstrual products in detention centers). 
and use taxes on such products as though they are "non-essential" goods; ${ }^{8}$ and not permitting menstruators to bring their own products into the bar exam. ${ }^{9}$

\section{Dignity}

These are all deeply flawed policies and practices, but why do they implicate dignity? My answer is twofold: our periods are so deeply personal, relating directly to principles of bodily integrity ${ }^{10}$ and our ability to manage them safely and affordably affects our ability to engage fully with the external world. ${ }^{11}$ An affront to dignity around menstruation both reinforces the negative messages we receive about our bodies and reiterates the message that if we are bleeding - whether as women, trans men, or gender queer individuals - we do not belong. ${ }^{12}$

\footnotetext{
${ }^{8}$ Period Equity launched its "Tax Free. Period." campaign in 2019 to end taxation on menstrual products and continues to challenge its constitutionality. See 30 States Have Until Tax Day 2021 To Eliminate Their Tampon Tax, TAX FreE. PERIOD. (Apr. 15, 2020), https://www.taxfreeperiod.com/blog-entries/weredemanding-that-30-states-become-tax-free-period-by-tax-day-2021_[https://perma.cc/9HHW-PBXH]; Suzanne Herman, A Blood-Red-Herring: Why Revenue Concerns Are Overestimated in the Fight to End the "Tampon Tax", 48 FoRDHAM URB. L.J. 595 (2021) (discussing the tampon tax more generally).

${ }^{9}$ See Marcy L. Karin, Margaret E. Johnson \& Elizabeth B. Cooper, Menstrual Dignity for Bar Examinees, 55 U.C. DAvis L. REV. (forthcoming Nov. 2021); Elizabeth Cooper, Margaret Johnson \& Marcy Karin, Punishing Bar Exam Policies on Menstrual Products Must Go, LAw360 (Feb. 25, 2021, 5:36 PM), https://www.law360.com/articles/1358884 [https://perma.cc/JW74-UJVJ]; Elizabeth B. Cooper, Margaret E. Johnson \& Marcy L. Karin, Menstrual Products and the Bar: Advocacy Seeks to Create Equal Bar Exam Testing Conditions for Menstruators, Best PraC. FOR Legal Educ. (Aug. 5, 2020), https://bestpracticeslegaled.com/2020/08/05/menstrual-products-and-the-bar-advocacy-seeks-to-create-equalbar-exam-testing-conditions-for-menstruators/ [https://perma.cc/634J-BYN9].

${ }^{10}$ See, e.g., Judy Blume, Are You There God? It's Me, Margaret (1970). We are rarely ambivalent about our periods. We often are thrilled - and scared — when we first get it. Some may grow to resent it, especially if it causes physical pain and discomfort. Some cannot wait for menopause when others will mourn their lack of menses. Id. See also infra notes 19-20.
}

${ }^{11}$ See supra notes $5-9$ and accompanying text.

${ }^{12}$ See Chris Bobel \& Breanne Fahs, The Menstrual Mark: Menstruation as Social Stigma, in PALgRAVE HANDBOOK, supra note 7, at 193 ("Clearly, the stigmatized status of menstruation has detrimental consequences for girls' and women's self-esteem, body image, self-presentation, and sexual health.”). 
There are countless theories of dignity that can inform this discussion..$^{13}$ First, in law, the Supreme Court has employed the concept of dignity in numerous contexts ${ }^{14}$-most powerfully in a quartet of LGBTQ cases decided over two decades. ${ }^{15}$ Fundamentally, the Court recognized dignity as a counterweight to stigma, ultimately holding in Obergefell $v$. Hodges that laws that historically "impose stigma and injury" cannot withstand constitutional scrutiny. ${ }^{16}$ Thus, the Court envisions dignity to be the opposite of, and perhaps an antidote to, stigma. ${ }^{17}$

Second, in the medical setting, dignity is understood as deeply tied to autonomy: without the latter, one cannot have the former.$^{18}$ Historically, autonomy developed from the concept of bodily integrity, ${ }^{19}$ but it has evolved to encompass richer dimensions of informed consent that embrace the values of self-determination and dignity. ${ }^{20}$ In the

\footnotetext{
${ }^{13}$ See Nora Jacobson, A Taxonomy of Dignity: A Grounded Theory Study, 9 BMC InTL. HEALTH \& HuM. RTS. 3, 6 (2009) (describing the "ubiquity [of] the idea of dignity" and its use "in theology, philosophy, law, political theory, sociology, medicine, and nursing" among other disciplines).

${ }^{14}$ See Leslie Meltzer Henry, The Jurisprudence of Dignity, 160 U. PA. L. REv. 169, 178, 189-220 (2011) (noting that the word "dignity" appears in almost 1,000 Supreme Court opinions and that the Court increasingly relies on the concept); see also Noah B. Lindell, The Dignity Canon, 27 Cornell J.L. \& PuB. POL'y 415, 467 (2017) (reporting that dignity has helped to shape Eighth Amendment and Due Process jurisprudence).

${ }^{15}$ Elizabeth B. Cooper, The Power of Dignity, 84 Fordham L. REV. 3, 8-12 (2015) (describing the Supreme Court's growing dignity jurisprudence from Romer v. Evans, 517 U.S. 620 (1996), through Lawrence v. Texas, 539 U.S. 558 (2003), U.S. v. Windsor, 570 U.S. 744 (2013), and Obergefell v. Hodges, 576 U.S. 644 (2015)).

16576 U.S. 644, $671(2015)$.

${ }^{17}$ See infra notes 47-53 and accompanying text discussing stigma.

18 See Yvonne Lindgren, From Rights to Dignity: Drawing Lessons from Aid in Dying and Reproductive Rights, 2016 UTAH L. REV. 779, 818 (2016) ("Dignity is particularly well-suited to function as a guiding value in the context of rights related to healthcare as it is most frequently invoked by the courts to describe aspects of liberty, autonomy, and self-determination.”).

${ }^{19}$ See Elizabeth B. Cooper, Testing for Genetic Traits: The Need for a New Legal Doctrine of Informed Consent, 58 Maryland L. Rev. 346, 370-76 (1999); Ruth FAden AND Tom BeAuchamp, A History AND THEORY OF INFORMED CONSENT (1986).
}

${ }^{20}$ See Celia B. Fisher \& Matthew Oransky, Informed Consent to Psychotherapy: Protecting the Dignity and Respecting the Autonomy of Patients, 64 J. Clin. PSyCHOL. 576-88 (2008) ("Well-implemented informed 
medical context, "this right to self-determination is primarily a negative right to noninterference: the right to make decisions concerning one's own life for oneself without being controlled by others." ${ }^{21}$ Somewhat relatedly, the psychologists who developed selfdetermination theory describe it and its elements - autonomy, competence, and the capacity to develop relationships - as essential for one's intrinsic well-being. ${ }^{22}$

Perhaps the conceptualization of dignity that best captures the principles found in these legal, medical, and psychological conceptions - and that speaks to the private/public experience of menstruation described supra — is bioethicist Nora Jacobson's explication of "social dignity," which she identifies as having two related parts: dignity-of-self and dignity-in-relation. ${ }^{23}$ Dignity-of-self addresses self-respect and self-worth. ${ }^{24}$ Dignity-in-relation describes how individuals are treated by other people, organizations, or entities, and is defined by "the mores and traditions of a particular community or society." 25

In Jacobson's model, every interaction can violate or promote dignity (a "dignity encounter"). ${ }^{26}$ Violations typically happen when the action occurs in "harsh

consent procedures demonstrate ... respect for clients' right to self-determination" and enhance 'mutual trust."').

${ }^{21}$ Maartje Schermer, Autonomy in Medical Ethics: Issues of Informed Consent, in THE DiFFERENT FACES OF AutonOMY 23, 23 (Maartje Schermer ed., 2002) (noting that “"autonomy' is generally understood as the patient's right to self-determination within the context of medical and research practices").

${ }^{22}$ Elizabeth B. Cooper, The Appearance of Professionalism, 71 FLA. L. REv. 1, 43 (2019); Richard M. Ryan \& Edward L. Deci, Self-Determination Theory and the Role of Basic Psychological Needs in Personality and the Organization of Behavior, in HandBook Of Personality: TheORy And ReSEarch 654, 658 (Oliver P. John et al. eds., 3d ed. 2008) (identifying "only three basic and universal psychological needs: those for autonomy, competence, and relatedness.").

${ }^{23}$ See Jacobson, supra note 13. Jacobson also distinguishes human dignity from social dignity. The former, she notes, "is the abstract, universal quality of value that belongs to every human being simply by virtue of being human" and "cannot be created or destroyed." Id.

${ }^{24}$ See Jacobson, supra note 13, at 6, 10 (noting that dignity-of-self "is identified with characteristics like confidence and integrity" and is concerned with "the body, moral agency, and personhood").

${ }^{25} I d$. at 6 (stating that "respect and worth are conveyed through individual and collective behavior"). Jacobson observes that dignity-in-relation is concerned with "autonomy, status, and citizenship." Id. at 10. Further, "[b]ecause they are socially produced, [dignity-of-self and dignity-in-relation] are also contingent: they can be measured, violated, or promoted." Id.

${ }^{26} I d$. at 6 . 
circumstances" and the actors occupy two different positions, one of vulnerability and the other of antipathy. ${ }^{27}$ Fundamentally, there must be an asymmetry of "power, authority, knowledge, wealth, or strength." 28 When the disparity exists on a societal level, "racism or sexism or economic disparity flourish."29

The personal and societal dignity violations experienced by menstruators fit perfectly within Jacobson's paradigm. Individuals can experience lowered self-esteem-a diminished dignity-of-self - when others (individuals or organizations) treat them poorly or embarrass them about their periods. ${ }^{30}$ On the systemic level, when organizational and governmental policies - springing from ignorance or antipathy-broadly harm menstruators, dignity-in-relation is eroded. ${ }^{31}$

Although innumerable factors contribute to the dignitary harms experienced by menstruators, I focus on three: Invisibility, Stigma, and Racism/Classism. It is difficult to separate these interdependent social forces, but analyzing them independently will provide the foundation for a strategy to disrupt, and ultimately eliminate, menstruationbased dignity violations.

\section{Invisibility}

To some policy makers and employers, women generally and menstruators more specifically, are invisible. Recall the experiences of the first women admitted to law

\footnotetext{
${ }^{27} I d$. at 7 (defining "harsh circumstances" as "hierarchical and rigid, full of distraction and stress and urgency, but lacking in resources").

${ }^{28} \mathrm{Id}$.

${ }^{29}$ Jacobson, supra note 13 , at 7 . Other factors affecting the severity of the dignitary harm include whether past violations have occurred and the duration or frequency of the harms. Id. at 8. Jacobson notes: "Grouping, labeling, vilification, and discrimination often co-occur, for example, forming social order-level phenomena known as racism, when directed at individuals or groups of color, or stigma, when directed at individuals or groups whose identities have been 'spoiled' by a discrediting difference." Id.

${ }^{30}$ A lessened dignity-of-self also can be understood through the lens of constitutional law (dignity), bioethics (autonomy), and psychology (self-determination). Id.

${ }^{31}$ See Elizabeth B. Cooper, Social Risk and the Transformation of Public Health Law: Lessons from the Plague Years, 86 IowA L. REv. 869, 877 (2001) ("'[T]he enactment of policies that increase stigma or social hostility, in the absence of a compelling state interest, constitutes an avoidable and unacceptable harm to human dignity.").
} 
school or medical school for whom no one thought to create a bathroom. ${ }^{32}$ Consider the countless times women come up with wonderful ideas that are heard and accepted only when later articulated by men. ${ }^{33}$ Think, too, of the ways women are expected to present themselves sartorially_-far more ornately than their male peers and partners, who will be seen and heard in a comparatively bland pair of khakis and a button-down shirt. ${ }^{34}$

The invisibility of transgender individuals is somewhat more complex. Many have remained closeted out of fear of violence, losing their jobs, or social ostracism. ${ }^{35}$ Laws and workplace policies have only recently started to change, largely in response to demands by trans and gender non-confirming individuals and their allies. ${ }^{36}$ Still, the needs of trans men and gender non-binary individuals who also may menstruate are rarely, if ever, considered. ${ }^{37}$

Those with the power to create government policies, improve workplace practices, and facilitate access to public accommodations continue to overlook menstruators and

\footnotetext{
${ }^{32}$ See, e.g., Clara J. Bates, The Harvard Pee-In of 1973, HARv. Crimson (Nov. 1, 2018), https://www.thecrimson.com/article/2018/11/1/harvard-pee-in-1973/ [https://perma.cc/PSU6-SBV4]; Marc Wortman, The Last Barrier, YALE MED. MAG. (Summer 1998), https://medicine.yale.edu/news/yalemedicine-magazine/the-last-barrier/_[https://perma.cc/LB4P-AHY5].

${ }^{33}$ See Zameena Meja, How to Combat 'Hepeating' at Work, According to a Harvard Professor, CNBC (Oct. 11, 2017), https://www.cnbc.com/2017/10/11/how-to-combat-hepeating-at-work-according-to-a-harvardprofessor.html [https://perma.cc/Q7CS-4FKH] (describing this phenomenon as "hepeating"); see also Mary Katherine Tramontana, Why Are Men Still Explaining Things to Women?, N.Y. TimES (Sept. 9, 2020), https://www.nytimes.com/2020/09/09/us/why-are-men-still-explaining-things-to-women-mansplainingauthority-gender.html [https://perma.cc/JPS2-8SY6] (describing "mansplaining" as a presumption that women are "less knowledgeable, less competent, and somehow in need of a man to explain things to her").

${ }^{34}$ Cooper, supra note 22, at 12 n.40.

${ }^{35}$ See 2017 Workplace Equality Fact Sheet, Out \& EQUAL (Nov. 15, 2017), https://outandequal.org/2017workplace-equality-fact-sheet/ [https://perma.cc/5L57-5US9].

${ }^{36}$ See Know Your Rights, NAT’L CTR. FOR TRANSGENDER EQUAL, https://transequality.org/know-yourrights/employment-

general\#: :text=Your\%20employer\%20cannot\%20forbid\%20you,to\%20single\%20out\%20transgender\%20p eople [https://perma.cc/497M-GDAD].

${ }^{37}$ Email from a law professor parent of a transgender child to Professors Marcy L. Karin, Margaret E. Johnson, and Elizabeth B. Cooper in response to an op-ed written by Professors Karin, Johnson, and Cooper, Punishing Bar Exam Policies On Menstrual Products Must Go, Law360 (Feb. 25, 2021), https://www.law360.com/articles/1358884 [https://perma.cc/VLQ3-DBLC] (expressing gratitude to the authors for addressing the needs of trans and non-binary individuals) (on file with author).
} 
their needs. Consider the failure of emergency management personnel to include menstrual products in their provisions for affected individuals; ${ }^{38}$ the failure of schools to provide free and safe menstrual products to students — or their failure to place products in locations accessible to trans men and gender non-binary individuals (e.g., putting them only in women's bathrooms) ${ }^{39}$ the failure of state boards of law examiners to adopt safe and transparent menstrual policies; ${ }^{40}$ the failure of state tax boards to exempt menstrual products from state sales and use taxes, as is done with other essential products; ${ }^{41}$ and the failure of prisons and jails to provide free and safe products to those who are incarcerated, while recognizing their obligation to provide other necessities, such as toilet paper.

In each of these circumstances, those with policymaking authority either failed to consider providing menstrual products (i.e., the affected population was invisible), or they did not consider it important to do so. The resulting harm is tangible as menstruators rely on unhygienic substitutes for products, such as rags or toilet paper; use products longer than recommended, placing their health at risk; and barter other necessary items to obtain products. ${ }^{42}$ Further, countless people each year stay home from work or school to avoid the embarrassment of bleeding through their clothing, losing low-wage jobs where absence is not tolerated, and falling behind in their studies. ${ }^{43}$

As described supra, menstruators subjected to these policies experience not only these physical harms, but also individual dignitary harms that can affect their self-image

\footnotetext{
${ }^{38}$ See supra note 5.

${ }^{39}$ See Johnson, Waldman \& Crawford, supra note 6, at 250-57.

${ }^{40}$ See Karin, Johnson \& Cooper, supra note 9.

${ }^{41}$ See generally The History of the Tampon Tax, TAx Free. Period. (Mar. 18, 2020), https://www.taxfreeperiod.com/blog-entries/historytampontaxadvocacy [https://perma.cc/PN6T-LAB6]; Bridget J. Crawford \& Carla Spivack, Human Rights and Taxation of Menstrual Hygiene Products in an Unequal World, in TAX, INEQUALITY, AND Hum. RTs. (Philip G. Alston and Nikki Reisch eds., 2019) (arguing that tax reform is necessary because menstrual products are essential for health).

${ }^{42}$ See Amarica Rafanelli, Rags Instead of Tampons. Here's What Period Poverty Looks Like in the U.S., DiRECT ReliEF (Oct. 23, 2019, 6:07 AM), https://www.directrelief.org/2019/10/rags-instead-of-tamponsheres-what-period-poverty-looks-like-in-the-u-s/_[https://perma.cc/5UUK-J98B].

${ }^{43}$ See Ashley Rapp \& Sidonie Kilpatrick, Changing the Cycle: Period Poverty as a Public Health Crisis, UNIV. OF MiCH. (Feb. 4, 2020), https://sph.umich.edu/pursuit/2020posts/period-poverty.html [https://perma.cc/93H9-PTGW].
} 
and their self-confidence (dignity-of-self). ${ }^{44}$ Further, there are societal dignitary harms (dignity-in-relation) reflecting the message that the needs and experiences of menstruators just do not matter or that menstruators are not welcome. Indeed, if menstruators are not seen, then surely their needs will not be addressed.

\section{Stigma}

In Stigma: Notes on the Management of Spoiled Identity, ${ }^{45}$ Erving Goffman observed that stigma - the state of being disqualified from full social acceptance - not only is culturally-based and externally-driven, but also is often internally absorbed by the stigmatized person. ${ }^{46}$ Jacobson considers this person to lack dignity-of-self. ${ }^{47}$ Goffman, Jacobson, and others also help us to understand that a society and culture that stigmatizes an individual is but a short distance from adopting policies that embed stigma against such individuals and undercut the dignity of the stigmatized, often by enacting oppressive laws or failing to provide appropriate support. ${ }^{48}$ Jacobson understands such practices as the undermining of dignity-in-relation. ${ }^{49}$

Perhaps it should not be surprising that menstruation and people who menstruate are stigmatized and that the stigma has been so intractable: as far back as the Hebrew Testament, menstruation - and even contact with menstruators - was considered unclean and in some contexts reason for exile. ${ }^{50}$ Practices of separating people from the

\footnotetext{
${ }^{44}$ See supra notes 24-30 and accompanying text.

${ }^{45}$ Erving Goffman, Stigma: Notes on the Management of Spoiled Identity (1963).

${ }^{46} I d$. at 6-7.

${ }^{47}$ Jacobson, supra note 13, at 9.

${ }^{48}$ Kenji Yoshino, Covering (2006); Jessica D. Remedios \& Samantha H. Snyder, Intersectional Oppression: Multiple Stigmatized Identities and Perceptions of Invisibility, Discrimination, and Stereotyping, 74 J. OF SOC. Issues 265, 268-69 ("[S]tigmatized individuals who internalize outcomes that are actually due to discrimination may believe that they are less capable than their nonstigmatized peers.").

${ }^{49}$ See Jacobson, supra note 13, at 8; see also supra note 29 and accompanying text.

${ }^{50}$ See Leviticus 15:19-30 (stating, for example, that "when a woman has her regular flow of blood, the impurity of her monthly period will last seven days, and anyone who touches her will be unclean").
} 
community while menstruating continue to this day. ${ }^{51}$ Even in more progressive cultures, many menstruators go to great lengths to hide when they have their periods and often use euphemisms to attempt to disguise this fact. ${ }^{52}$

In this context, it is easy to understand why those in power, who often are cis-gender men (who do not menstruate), do not make it a priority to ask about menstruation or to develop policies that would require conversations about periods.

\section{Racism \& Classism}

People of Color and low-income individuals, two populations that overlap significantly due to our country's history of racist laws of exclusion, ${ }^{53}$ experience a policy-based double-bind. When it comes to policing in the streets and in the home (through often misguided child welfare policies), low-income People of Color receive far too much government attention, resulting in disproportionately high incarceration rates and removal of their children. ${ }^{54}$ When it comes to dignity-enhancing government

\footnotetext{
${ }^{51}$ See Emily Vaughn, Menstrual Huts Are Illegal in Nepal. So Why Are Women Still Dying in Them?, NPR (Dec. 17, 2019), https://www.npr.org/sections/goatsandsoda/2019/12/17/787808530/menstrual-huts-areillegal-in-nepal-so-why-are-women-still-dying-in-them [https://perma.cc/UT8D-6E34] (discussing the Hindu practice of "chhaupadi" in which women are exiled to huts while menstruating because they are considered "unclean"); Jill Litman, Menstruation Stigma Must Stop. Period., Pub. Health Advoc. (June 5, 2018), https://pha.berkeley.edu/2018/06/05/menstruation-stigma-must-stop-period/ [https://perma.cc/4B5F-SFZA] (discussing how some Venezuelan women are exiled to huts while menstruating and some menstruating Ghanaian women are prohibited from entering a house where there is a man).

52 Top Euphemisms for "Period" by Language, Clue (Mar. 10, 2016), https://helloclue.com/articles/culture/top-euphemisms-for-period-by-language [https://perma.cc/QXF3VVQ9].

${ }^{53}$ In 2019, People of Color in the United States made up 51.9\% of the poverty population, despite making up only $31.9 \%$ of the general population. John Creamer, Inequalities Persist Despite Decline in Poverty for All Major Race and Hispanic Origin Groups, U.S. Census BurEAu (Sept. 5, 2020),

https://www.census.gov/library/stories/2020/09/poverty-rates-for-blacks-and-hispanics-reached-historiclows-in-2019.html [https://perma.cc/428M-QQPK]. See generally HeATHER MCGHEE, THE Sum of Us (2021) (identifying racism as the basis for many failures of American policy); IBRAM X. KENDI, STAMPED FROM THE BeginNing: The Definitive History OF RACIST IDEAS IN AMERICA (2017) (tracing how racist ideologies fundamentally shaped American laws and culture); RiCHARD ROTHSTEIN, THE COLOR OF LAW (2017) (explaining how U.S. laws and policies deliberately segregated the country).
}

${ }^{54}$ See generally Breonna Taylor: Timeline of Black Deaths Caused by Police, BBC News (Jan. 6, 2021), https://www.bbc.com/news/world-us-canada-52905408_https://perma.cc/8DHL-USYH]; MicHELLE Alexander, The New Jim Crow (2010) (explicating the policies behind the mass incarceration of People of 
programs, however, these same individuals often seem invisible to law-makers; in reality, they often are deliberately overlooked. ${ }^{55}$

In the context of menstruation, low-income People of Color are more likely than others to experience period poverty, understood as being unable to afford menstrual products, as well as having "inadequate access to toilets, hand washing receptacles, and hygienic waste management. ${ }^{n 6}$ Period poverty exists because federal government benefit programs rarely budget the need for menstrual products or permit benefits to be spent on them ${ }^{57}$ and because menstrual products are so expensive (and still taxed by over thirty states) ${ }^{58}$ A person who menstruates is likely to spend thousands of dollars over a lifetime to attend to their period. ${ }^{59}$ Further, the quality of products can vary significantly by price. Cheaper tampons can be made of low-quality cotton packaged in cardboard that are uncomfortable and hard to use, in contrast to those made of organic materials that reduce

Color); Dorothy Roberts, Shattered Bonds: The Color of Child Welfare (2002); Clare Huntington, Rights Myopia in Child Welfare, 53 UCLA L. REv. 637, 657 (2005) (describing how "African American children are removed at greater rates than similarly situated white and Latino children, and receive less effective services.”).

${ }^{55}$ See Jamila Michener \& Margaret Teresa Brower, What's Policy Got to Do With It?: Race, Gender, and Economic Inequality in the United States, 149 J. Am. ACAD. ArTs \& Sci. 100, 102 (2020); U.S. SenAte, Joint Economic Committee, The Economic State of Black America in 2020 11-14 (2020).

${ }^{56}$ Rapp \& Kilpatrick, supra note 43 ("Period poverty especially prevents low-income menstruators from bleeding with dignity.”).

${ }^{57}$ See Linda Carroll, Even in the U.S., Poor Women Often Can't Afford Tampons, Pads, Reuters (Jan. 10, 2019, 5:37 PM), https://www.reuters.com/article/us-health-menstruation-usa/even-in-the-u-s-poor-womenoften-cant-afford-tampons-pads-idUSKCN1P42TX [https://perma.cc/9A2H-NE52] (stating that menstrual products are not covered under government programs, such as WIC and SNAP).

${ }^{58}$ Food or Tampons? No One Should Have to Choose, PERIOD EQuiTy, https://www.periodequity.org/issues [https://perma.cc/59AP-HRNJ]; 30 States Have Until Tax Day 2021 To Eliminate Their Tampon Tax, supra note 8 .

${ }^{59}$ See Jennifer Weiss-Wolf, U.S. Policymaking to Address Menstruation: Advancing an Equity Agenda, 25 WM. \& MARY J. OF RACE, GENDER, AND SOC. JUST. 493, 500 (2019). 
exposure to harsh chemicals. ${ }^{60}$ Newer or revamped products on the market, such as period underwear and menstrual cups, are particularly expensive. ${ }^{61}$

Although some states are starting to provide menstrual products through school programs $^{62}$ (and less frequently in prisons ${ }^{63}$ ), the harm to individuals and communities is incalculable. Consider the young woman of color who does not attend school when bleeding heavily because she does not have access to products. In turn, she falls behind and may be unable to obtain her high school diploma or may not be seen as qualified for jobs requiring more polished credentials. Working a low-wage job, her inability to obtain menstrual products may not improve - and too many absences can lead to being fired. The risks she faces are both physically tangible (e.g., infections, irritation), socially compromising (e.g., school and work absences), and emotionally challenging (e.g., anxiety, depression). ${ }^{64}$ Further, the damage to her economic self-sufficiency, self-image, and dignity — and the attendant social costs and destruction of relational dignity — are immeasurable. ${ }^{65}$

\footnotetext{
${ }^{60}$ See Karin, Johnson \& Cooper, supra note 9 (quoting a bar examinee who stated that cardboard tampons were uncomfortable); Emilia Benton, What Are Organic Tampons-And Should I Start Using Them?, WOMEN's HEALTH (Mar. 11, 2019), https:/www.womenshealthmag.com/health/a26661269/organic-tamponbrands/ [https://perma.cc/NAC5-8J5E] (describing organic tampons as useful for reducing sensitivity and chemical exposure).

${ }^{61}$ See Shannon Palus \& Nancy Redd, The Best Period Underwear, N.Y. Times (Dec. 3, 2020), https://www.nytimes.com/wirecutter/reviews/thinx-period-panties/ [https://perma.cc/Z6NJ-7V2P]; Edith Zimmerman, Do You Have a Moment to Talk About Menstrual Cups?, The Cut (Apr. 5, 2019), https://www.thecut.com/2019/04/have-menstrual-cups-finally-gone-mainstream.html [https://perma.cc/64E5MXJX].

${ }^{62}$ See Jennifer Calfas, More States Consider Free Tampons in School Bathrooms, Wall St. J. (Feb. 25 , 2020, 5:30 AM), https:/www.wsj.com/articles/more-states-consider-free-tampons-in-school-bathrooms11582626601 [https://perma.cc/3XTU-BJLD] ("More than a dozen state legislatures have recently introduced bills that would require public schools to supply free tampons and other menstrual products in their bathrooms.").

${ }^{63}$ As of 2019, thirty-eight states did not have laws requiring prisons to provide menstrual products to incarcerated individuals. Kimberly Haven, Why I'm Fighting for Menstrual Equity in Prison, ACLU (Nov. 8, 2019), https://www.aclu.org/news/prisoners-rights/why-im-fighting-for-menstrual-equity-in-prison/ [https://perma.cc/A684-SUFJ].

${ }^{64}$ Rapp \& Kilpatrick, supra note 43.

${ }^{65}$ See Jacobson, supra note 13, at 11 (describing the negative "collective health impacts resulting from injuries to dignity that are both very broad and very narrow in scope").
} 


\section{Next Steps}

As large and structurally based as these problems are, menstruators, women more generally, and our allies, can address these concerns - and doing so will lead to the development of sound menstrual policies rooted deeply in dignity. Indeed, Jacobson's construction of social dignity would support the principle that all individuals (including non-menstruators and cis-gender men) are responsible for reducing and eliminating menstruation-related dignity violations.

Admittedly, the three causes of menstrual indignity discussed in this EssayInvisibility, Stigma, and Racism/Classism — are systemic and must be dismantled for the countless harms they cause. Activists and advocates labor for decades to lay the foundation for seismic movements, dreaming big even when focusing on more discrete abrogations of social justice. But change is possible, perhaps all the more so when individual and societal harms are so blatant.

Indeed, women are holding more leadership positions and are more visible in the workforce than just a decade ago. With their seniority and attendant power comes the capacity to seek meaningful policy reform. ${ }^{66}$ The \#MeToo movement also has created a greater focus on workplace policies - and women's dignity in the workplace - than ever before ${ }^{67}$ The Black Lives Matter movement-founded by three women - is challenging power structures in the workplace, in government, and in local communities in ways not seen since the civil rights movement. ${ }^{68}$

More specific to menstruation, the millennial generation is using everything from social media to public protests to bring periods out of the closet, encouraging public

\footnotetext{
${ }^{66}$ See The Data on Women Leaders, Pew Rsch, CtR. (Sept. 13, 2018), https://www.pewresearch.org/socialtrends/2015/01/14/chapter-3-obstacles-to-female-leadership/ [https://perma.cc/CBP9-BAMN] (showing the increase in the number of women in leadership roles across different industries); see also Alice H. Eagly, Once More: The Rise of Female Leaders, Am. Psych. Ass'N (Sept. 8, 2020), https://www.apa.org/research/action/female-leaders [https://perma.cc/PH4L-D99V] (describing how an increase in female leaders increases the public good).

${ }^{67}$ See Nicole Lyn Pesce, The \#MeToo Movement has Changed Policies Across Industries, but There's Still Work to be Done., MARKETWATch (Oct. 4, 2018, 6:59 PM), https://www.marketwatch.com/story/the-metoomovement-has-changed-policies-across-industries-but-theres-still-work-to-be-done-2018-10-04 [https://perma.cc/ELJ2-SVNW].

${ }^{68}$ Herstory, supra note 3.
} 
discussion of a topic previously too stigmatized to discuss publicly. ${ }^{69}$ Women have founded new organizations to ensure enactment of just laws and policies that reflect the dignity that individual menstruators, and our society, deserve. ${ }^{70}$

These efforts are creating real change: the federal government now classifies menstrual products as medical expenses $;^{71}$ some states have removed the sales tax levied on products; some school districts are starting to make free menstrual products available,$^{72}$ as are some prisons $;^{73}$ and the state boards of bar examiners that prohibited menstruators from bringing their own products to the bar exam have rolled back these policies. ${ }^{74}$ Although our work is far from over, these victories - all of which have occurred in the last five years - foreshadow the great change that is possible when we continue to work together to dismantle systemic oppression and ensure menstrual dignity for all.

\footnotetext{
${ }^{69}$ See Shannon Shelton Miller, Putting a Stop to the Stigma Around Menstruation, HeAlthy Women (Apr. 27, 2020), https://www.healthywomen.org/content/article/putting-stop-stigma-around-menstruation [https://perma.cc/28SE-25CF] ("Gen Z activism has included Girl Scouts advocating to make menstrual products available in their school bathrooms."); Corey Stieg, Here's How Wellness Bloggers Are Rebranding Periods, Refinery 29 (Aug. 22, 2018), https://www.refinery29.com/en-us/period-instagram-postsmenstruation-taboo [https://perma.cc/79Q7-6LRK] (discussing how younger individuals are openly posting about menstruation on platforms such as Instagram and YouTube).

${ }^{70}$ See, e.g., Founders, PERIOD EQUITY, https://www.periodequity.org/founders [https://perma.cc/V5WUFPMM] (listing Jennifer Weiss-Wolf and Laura Strausfeld as the co-founders).

${ }^{71}$ See Goldberg, supra note 6.

${ }^{72}$ See Johnson, Waldman \& Crawford, supra note 6, at 255-56.

${ }^{73}$ See Evan Simko-Bednarski, Federal Prisons Required to Make Tampons, Pads Available, CNN (Aug. 29, 2017), https://www.cnn.com/2017/08/29/health/federal-prisons-free-tampons-pads [https://perma.cc/Z42N9DB9].

${ }^{74}$ See Karin, Johnson \& Cooper, supra note 9.
} 